\title{
THE ANATOMY OF THE EXTERNAL STRIATED URETHRAL SPHINCTER
}

\author{
By Grannum R. Sant, B.A., M.B., B.Ch., B.A.O. \\ School of Pathology, Trinity College, and Meath Hospital, Dublin
}

IN cases of neurogenic bladder, failure of relaxation of the external sphincter can cause vesical outlet obstruction and interfere with normal voiding and bladder evacuation. This situation can be relieved by transurethral external sphincterotomy (Ross et al., I967; O’Flynn, I970).

The physiology of micturition and the functional anatomy of the vesical neck have been the subject of many reports, but, apart from the work of Manley (I966), the distribution of striated muscle fibres around the urethra in the region of the apex of the prostate and the verumontanum has not been extensively studied.

This study was undertaken with the object of detailing the normal anatomy of the external urethral sphincter and its possible influence on the technique of transurethral external sphincterotomy.

\section{MATERIALS AND METHODS}

Specimens of bladder, including the distal ureteric segments, urethra and penis in continuity, were obtained at necropsy from ro male subjects. Thses ranged in age from I 6 to 76 years, with no history of infection or anomaly of the urinary tract. The ureters and penis were tied following the introduction of $100 \mathrm{ml}$. of Io per cent. formol-saline into the bladder. The entire specimen was then fixed in $500 \mathrm{ml}$. of formol-saline for one week.

Serial transverse blocks of the urethra up to and including the bladder neck were then obtained. The anterior surface of the urethra in each block was marked with india ink for future reference. Following further fixation for 7 days, the blocks were sectioned serially at Io $\mu$ intervals. Every tenth section was stained with haematoxylin and eosin. Appropriate intermediate sections were also stained by Van Gieson's method. The sections were then examined microscopically.

\section{RESULTS}

The wall of the male posterior urethra comprises an inner longitudinal and an outer circular layer of smooth muscle. Both arise from the bladder musculature, and the outer layer is oblique for most of its course, diminishing in thickness as it passes distally (Tanagho \& Smith, I966).

Microscopic examination revealed the presence of striated fibres of the external sphincter in both the membranous and prostatic segments of the urethra. The course and distribution of the fibres varied, and two contiguous, but anatomically different components of the sphincter were identified.

The firs1 component is a dense aggregation of circular striated fibres in the region of the membranous urethra. It was external to the longitudinal urethral smooth muscle layer and extended for a distance of $85 \mathrm{~mm}$. to $\mathrm{I} 40 \mathrm{~mm}$. (average 


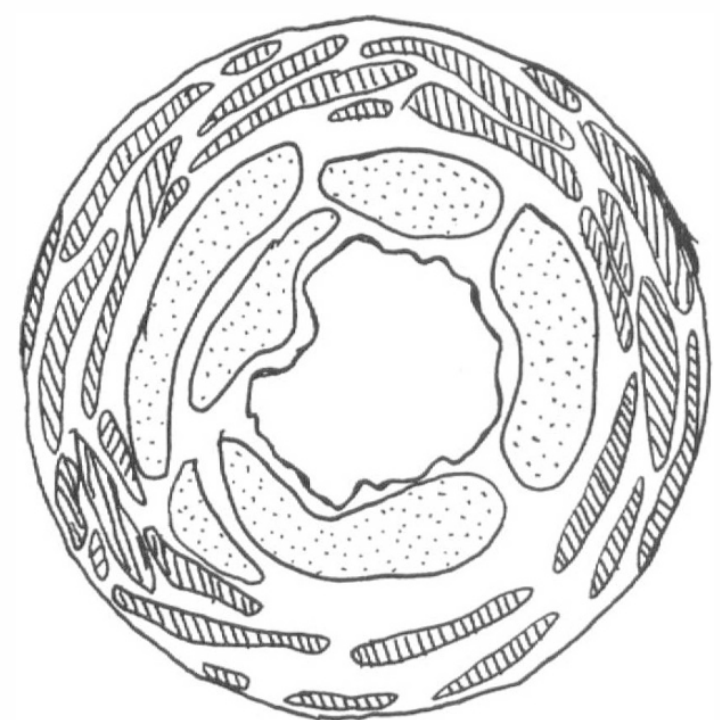

A

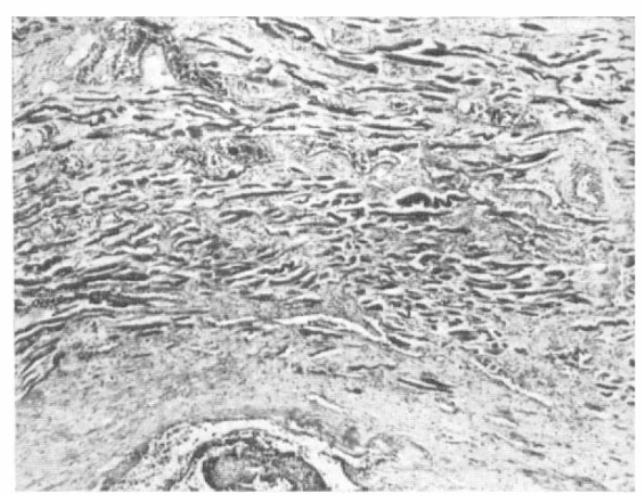

FIG. I

B

Cross-section at the level of the membranous urethra. A, Schematic drawing showing distribution of striated fibres circularly with a relative deficiency posteriorly. B, Microscopic section of $(\mathrm{A})$, showing circular distribution of striated fibres. H. and E. $\times 25$.

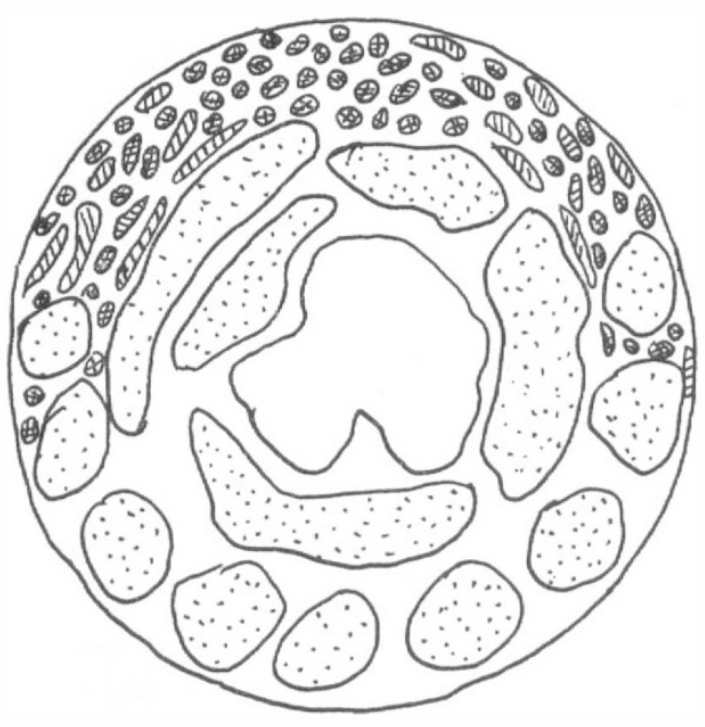

A

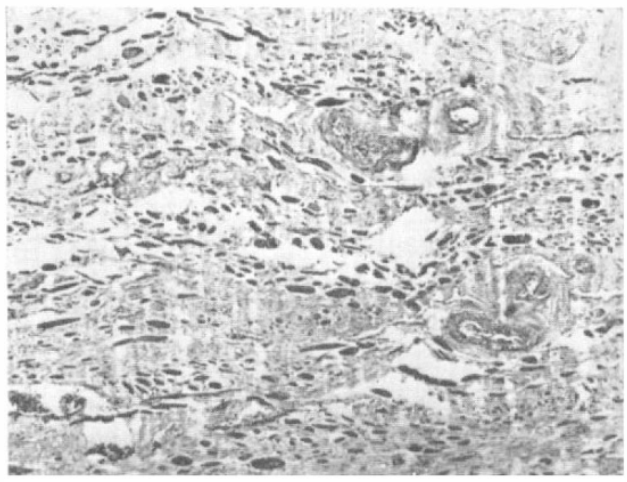

FIG. 2
B

Cross-section at the level of the prostatic urethra. A, Schematic drawing showing distribution of striated fibres longitudinally with a complete deficiency posteriorly. B, Microscopic section of anterior part of $(\mathrm{A})$, showing anterior longitudinal striated fibres cut transversely. H. and $\mathrm{E} . \times 25$. 
I IO mm.). In eight of the specimens the striated muscle was completely circumferential (fig. I, A and B), whereas in the remaining two it was deficient posteriorly.

The second component is composed of longitudinal striated fibres on the anterior aspect of the urethra. It extends for a distance of 100-130 $\mathrm{mm}$. (average I $5 \mathrm{~mm}$.) from the proximal limit of the first component into the prostatic urethra. Posteriorly the fibres are completely deficient (fig. 2, A) and anteriorly they taper off and become deficient anterolaterally until they insert into the distal border of the outer oblique layer of urethral smooth muscle (fig. 2, B). Connecting the two components is an intermediate area of mixed circular and longitudinal fibres, distributed anterolaterally for an extent of 30-40 $\mathrm{mm}$.

\section{DISCUSSION}

A reorientation of the axis of the outer smooth muscle layer of the urethra has been postulated as the cause of the pre-voiding drop in proximal urethral pressure (Tanagho \& Miller, I970). The anterior longitudinal component of the striated sphincter can, by virtue of its attachment to the smooth muscle, mediate this reorientation.

The obliquity of the outer smooth fibres varies indirectly with its length and the intra-urethral pressure (Mitchell, 1965). In the pre-voiding stage of micturition the external sphincter relaxes (Petersen \& Franksson, 1955) and it is suggested that the resultant decrease in the tone of the anterior longitudinal component releases the tension on the distal border of the outer circular smooth muscle. This causes an increase in the obliquity of the smooth muscle, accompanied by a decrease in its closure efficiency and resultant voiding.

A spastic obstruction at the level of the circular component of the striated sphincter occurs in some cases of paraplegic bladders (Ross et al., 1958). Accepting the postulated function of the anterior longitudinal component, another contributory factor to the deranged physiology of paraplegic bladders is apparent. Nonrelaxation of a spastic anterior longitudinal component makes it impossible to increase the obliquity of the urethral smooth muscle and this results in an inability to initiate voiding. This leads to the complications of stress and overflow incontinence.

Ideally, division of the sphincter in external sphincterotomy should affect the integrity of both components of the sphincter. The point on the circumference most likely to result in this seems to be anterolaterally, i.e. in the region where the circular fibres turn proximally to run up the anterior wall of the prostatic urethra.

\section{SUMMARY}

An anatomical study of the external sphincter of the urethra is presented. Around the membranous urethra the fibres are arranged circularly, giving off a constant anterior longitudinal prolongation into the prostatic urethra. It is postulated that the obliquity of the outer smooth muscle layer of the urethra is controlled by the anterior longitudinal component of the sphincter. An anterolateral sphincterotomy is suggested as the best method of external sphincterotomy.

\section{RÉSUMÉ}

Une étude anatomique du sphincter externe urétral est presentée. Les fibres ont une disposition circulaire au niveau de l'urethra membraneuse se prolongeant antérieurement et 
longitudinalement dans l'urètre prostatique. Il a été postulé que l'obliquité de la musculature externe lisse de l'urètre est contrôlée par le composant longitudinal antérieur du sphincter. Une sphinctérotomie antéro-latérale est suggérée comme étant la meilleure méthode de sphinctérotomie externe.

\section{ZUSAMMENFASSUNG}

Ein Bericht über den Sphincter externus der Urethra wird gegeben. In der membranösen Urethra sind die Fasern cirkulär angeordnet mit einer longitudinalen Verlängerung in die prostatische Urethra hinein. Es wird postuliert, dass die Obliquidität der äusseren Muskelschicht der Urethra von der vorderen longitudinalen Komponente des Sphincters controlliert wird. Es wird als beste Methode der externen Sphincterotomy die antero-laterale Sphincterotomy vorgeschlagen.

Acknowledgments. I wish to thank Professor W. T. E. McCaughey, Professor D. O'B. Hourihane and Mr. J. D. O'Flynn for their continuous help, advice and encouragement. This study was supported by a grant from the Medical Research Council of Ireland.

\section{REFERENCES}

Manley, C. B. (I966). F. Urol. 95, 234.

Mitchell, J. P. (1965). General discussion at the 2ist Annual Meeting of the British Association of Urological Surgeons. Brit. F. Urol. 37, 648-649.

O'FLYNN, J. D. (I970). Personal communication.

PETERSEN, I. \& FRANKSSON, C. (I955). Electromyographic study of the striated muscles of the male urethra. Brit. F. Urol. 27, I48-I53.

Ross, J. C., GibBon, N. O. K. \& Damanski, M. (I967). Division of the external sphincter in the treatment of the neurogenic bladder-a ten-year review. Brit. F. Surg. 54, 627-628.

TANAGHo, E. A. \& SMITH, D. R. (I966). The anatomy and function of the bladder neck. Brit. F. Urol. 38, 54-7I.

TANAGHO, E. A. \& Miller, E. R. (1970). Initiation of voiding. Brit. F. Urol. 92, I75-I83. 